\title{
Rapunzel Syndrome- Rare Presentation Of Trichobezoar
}

\section{S Verma}

\section{Citation}

S Verma. Rapunzel Syndrome- Rare Presentation Of Trichobezoar. The Internet Journal of Surgery. 2010 Volume 28

Number 1 .

\begin{abstract}
Rapunzel syndrome a rare presentation occurs predominantly in young women or girls with psychiatric or emotional disorders and consists of trichobezoarwith a tail extending at least to the jejunum with symptoms suggestive of obstruction. With less than 40 cases reported in literature till date we report a case in a young female diagnosed clinico-radiologically and treated surgically with removal of an intact trichobezoar extending from stomach till the jejunum.
\end{abstract}

\section{INTRODUCTION}

Bezoars consist of nondigestible foreign material present in the stomach or intestine and are categorized by content into four categories. Phytobezoars originate from vegetable and plant matter, trichobezoars result from the ingestion of hair, lactobezoars, which consist of milk curd and pharmacobezoars or medication bezoars.

Rapunzel Syndrome is an uncommon presentation of trichobezoar, involving strands of swallowed hair extending as a tail through the small intestine, beyond the stomach. This was first described in 1968 by Vaughan et $\mathrm{al}^{1}$, with less than 40 cases reported till date. It is predominantly found in emotionally disturbed or mentally retarded youngsters with history of trichotillomania and trichophagia ${ }^{2}$, We report a case in a young girl with psychoneuronal disorder presenting with complaints of vomiting and progressive weight loss.

\section{CASE REPORT}

A 15 year old girl presented to us with complaints of persistent vomiting and progressive weight loss. On examination the patient was pale and cachexic in appearance. Her hemoglobin was $8 \mathrm{gm} / \mathrm{dl}$ with microcytic hypochromic picture on peripheral blood smear. Other routine blood examinations were within normal limits.

Barium examination revealed filling defect in stomach with persistent barium within the interstices of the filling defect seen extending into the duodenum and proximal jejunum on delayed barium examination film ( Figure 1). Based on this and clinical features possibility of Rapunzel syndrome was kept and on further questioning the patient's mother admitted that she had history of psychoneuronal disorder with a habit of pulling out her hair and secretly swallowing it.

\section{Figure 1}

Legend: Figure 1 Barim study film showing large gastric bezoar with its interstices filled with barium extending into duodenum and jejunum (arrows)

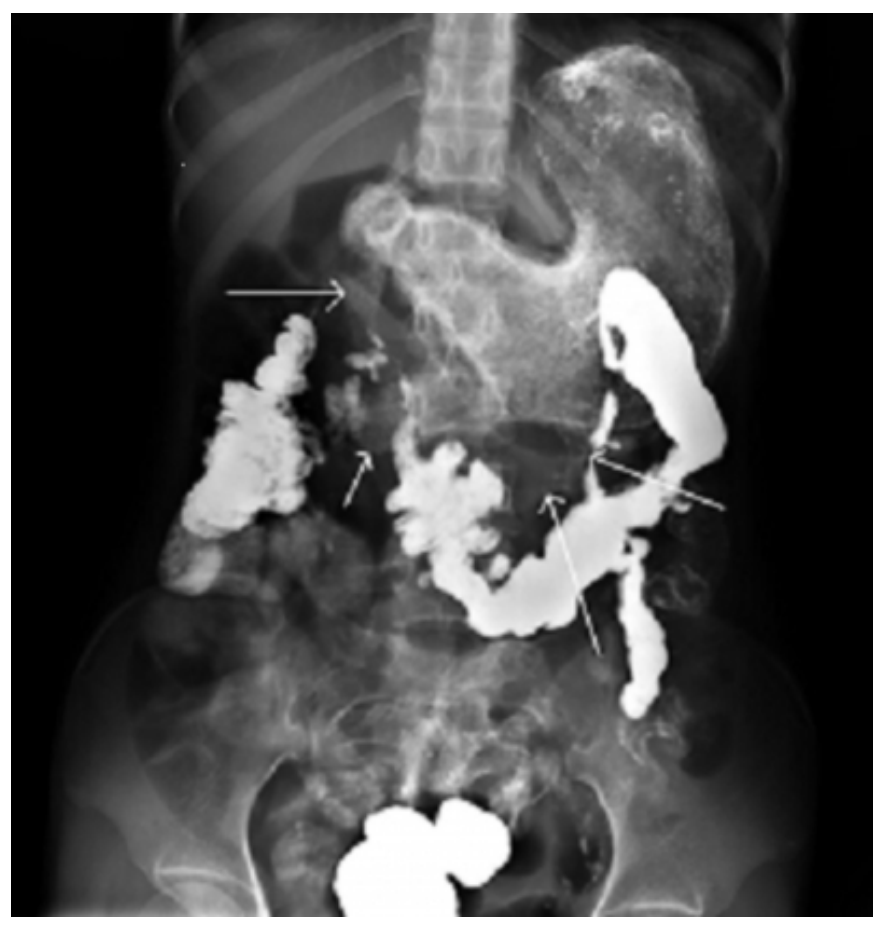

Gastrostomy was performed with gastrointestinal trichobezoar measuring around $75 \mathrm{~cm}$ in length removed intact. (Figure 2) 


\section{Figure 2}

Legend : Figure 2 Surgical specimen showing large intact gastrointestinal trichobezoar

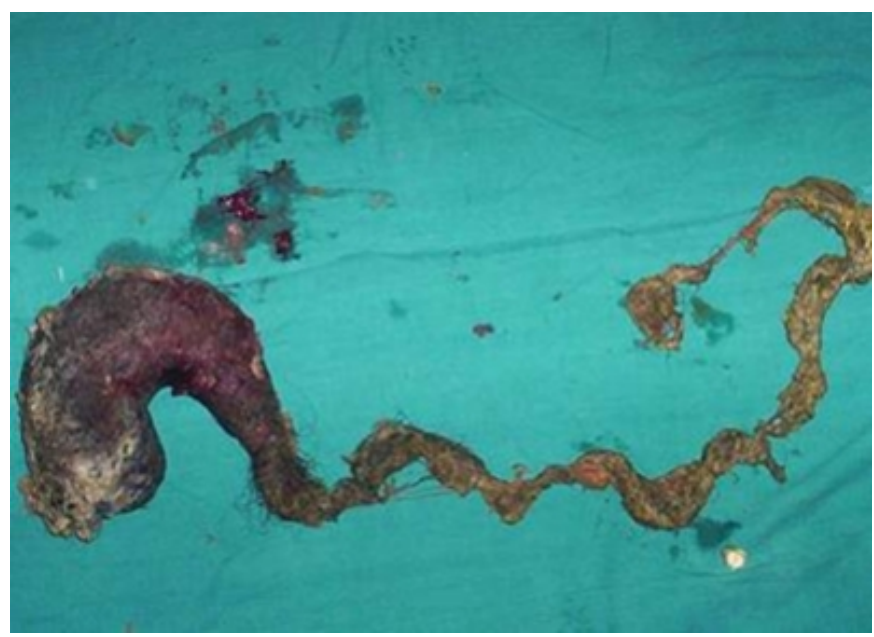

The patient's post operative recovery was uneventful and she was discharged after 2 weeks after psychiatric counseling of the patient and relatives and advise for regular follow up.

\section{DISCUSSION}

Rapunzel syndrome is named after a tale written in 1812 by the Brothers Grimm about a young maiden, Rapunzel, with long tresses who lowered her hair to the ground from high in her prison tower to permit her young prince to climb up to her window and rescue her. As per literature Rapunzel syndrome occurs predominantly in young women or girls with psychiatric or emotional disorders and consists of (1) a trichobezoar with a tail (2) extension of the tail at least to the jejunum, and (3) symptoms suggestive of obstruction. ${ }^{2}$

Most of the cases have been reported in countries where women traditionally have long hair. The most common presenting features are abdominal pain, nausea and vomiting, obstruction, and peritonitis. Uncommon presentations are weight loss, anorexia, hematemesis and intussusception $^{2}$

\section{DIAGNOSTIC MODALITIES}

An erect abdominal radiograph and a supine radiograph may show a mass floating in the stomach at the air fluid interface ${ }^{3}$ or a prominent gastric outline with an intragastric mottled mass, outlined by gas in the distended stomach, mimicking a food-filled stomach. ${ }^{4}$

Barium study demonstrates a mobile or immobile intraluminal filling defect of variable size, which may show extension into the duodenum and small bowel ${ }^{3,5}$. Barium remains in bezoar for hours after exiting remainder of bowel.
Delayed film will show retained barium in interstices of bezoar.,

Abdominal Ultrasound shows a dense, echogenic rim with sharp, clear posterior acoustic shadowing in the epigastric region. This characteristic appearance persists irrespective of the angulation of the transducer or alteration of position of the patient and is different from "dirty" shadowing generated by ingested gas and food within the stomach. ${ }^{4,6}$ However sonography is of limited sensitivity in revealing gastric bezoars. $^{6}$

Plain abdominal CT usually shows a mobile intragastric mass consisting of "compressed concentric rings", with a mixed density or mottled pattern due to the presence of entrapped air and food debris. ${ }^{3,4} \mathrm{CT}$ can be used to distinguish between retained food particles in the stomach and gastric bezoars visualized on an image. Small bezoars are rounded or ovoid, tend to float on the water-air surface surrounded by the gastric contents, and show lower density than food particles Large bezoars tend to fill all the lumen, exhibiting air bubbles diffusely distributed throughout the mass ${ }^{6}$.

The diagnosis can also be established by endoscopy, where trichobezoars are often found to have a hard, concrete like appearance and enzymatic oxidation of hair gives it a darkened colour. ${ }^{4,7}$

\section{TREATMENT}

Treatment options include endoscopic removal, chemical dissolution and mechanical fragmentation, for small bezoars. Surgery is usually necessary for large bezoars with extension into the bowel as seen in this case. The bezoar plus its tail can be removed via gastrotomy and sometimes multiple enterotomies to reduce risk of gut perforation, as long bezoar tails are often extremely adherent to the side of the gut wall. $^{4,8}$

\section{FOLLOW UP}

Psychiatric follow up is important and follow up care should be extended to family members, who should be vigilant with patients, since recurrences of the problem have been described. ${ }^{9}$ The need for adequate follow-up should be emphasized to avoid recurrences.

\section{CONCLUSION}

The Rapunzel syndrome is rare but should be taken into consideration in investigating cases of female patients with a history of vomiting, weight loss and anemia. Diagnostic 
modalities includes barium study, ultrasonography, abdominal computed tomography (CT) and endoscopy. Treatment is surgical in most cases.

\section{References}

1. Vaughan ED, Sawyers JL, Scott HW. The Rapunzel syndrome. An unusual complication of intestinal bezoar. Surgery 1968; 63:339-343.

2. Naik S, Gupta V, Naik S, Rangole A, Chaudhary AK, Jain $P$ et al.Rapunzel syndrome reviewed and redefined. Dig Surg 2007;24;157-161.

3. Eisenberg RL, Levine MS. Miscellaneous abnormalities of the stomach and duodenum. In: Gore RM, Levine MS, editors. Gastrointestinal radiology, 3rd ed. Philadelphia, USA: Saunders, 2008: 679-706.

4. Dindyal S,Bhuva Nj, Dindyal S, Ramdass
MJ,Narayansingh V. Trichobezoar presenting with the 'comma sign' in Rapunzel Syndrome: a case report and literature review. Cases J. 2008;1:286.

5. Hewitt AN, Levine MS, Rubesin SE,Laufer I. Gastric bezoars: reassessment of clinical and radiographic findings in 19 patients. Br J Radiol 2009; 82:901-907.

6. Ripolles T, Garcia-Aguayo G, Martinez MJ, Gil P.Gastrointestinal bezoars: sonographic and CT characteristics. Am J Roentgenol 2001;177(1):65-69. 7. Gonuguntla V, Joshi DD. Rapunzel syndrome:a comprehensive review of an unusual case of trichobezoar. Clin Med Res 2009;7(3):99-102.

8. Singla SL, Rattan KN, Kaushik N, Pandit SK. Rapunzel syndrome - a case report. Am J Gastroenterol. 1999;94:1970-1.

9. Frey AS,McKee M, King RA, Martin A. Hair apparent:Rapunzel Syndrome. Am J Psychiatry 2005; 162:242-248. 


\section{Author Information}

Sameer R. Verma, MD,DNB

Department of Radiodiagnosis, Subharti Medical College 